\title{
Diagnosis of Oesophagostomum columbianum infection in goat by indirect enzyme linked immunosorbent assay
}

\author{
R. $\mathrm{JAS}^{1^{*}}$, J. D. GHOSH ${ }^{1}, \mathrm{~K} . \mathrm{DAS}^{2}$ \\ ${ }^{1}$ Department of Veterinary Parasitology, ${ }^{2}$ Department of Veterinary Physiology, Faculty of Veterinary and Animal \\ Sciences, West Bengal University of Animal and Fishery Sciences; 37, Kshudiram Bose Sarani, \\ Kolkata 700 037, India, E-mail: ruma_k007@yahoo.co.in
}

\begin{abstract}
Summary
Oesophagostomosis is one of the most prevalent nematodosis with considerable economic losses in small ruminant livestock. Prepatent stage of Oesophagostomum columbianum is primarily involved in the major pathogenic effect of the infection and conventional methods are unable to detect this stage. An indirect enzyme linked immunosorbent assay (ELISA) was therefore standardized and evaluated for the purpose to improve diagnosis and thereafter minimize the economic losses due to this infection in goat. The eggs obtained from $O$. columbianum adult female worms, collected from caecum and colon of slaughtered goats, were cultured to obtain the third stage larvae $\left(\mathrm{L}_{3}\right)$. Crude somatic antigen (CSAg) was prepared from triturated worms. Experimental goats $(n=12)$ were orally infected each with $600 \mathrm{~L}_{3} / \mathrm{kg}$ body weight. Serum samples of the infected goats were collected at 2-day-interval from day-3 till day-33 post infection. The indirect ELISA was standardized using the CSAg for coating the wells, infected goat sera as binding antibody, anti-goat IgG-HRP conjugate and ortho-phenylenediamine (OPD) with peroxide as substrate. The sensitivity, specificity and accuracy of ELISA were determined by testing 96 serum samples of goats whose parasitological status after slaughter was determined by examination of the abomasums and the intestines. $O$. columbianum antibodies were detected in sera of infected goats on day $18-27$ post-infection with 96.00 , 73.91 and 85.42 per cent sensitivity, specificity and accuracy, respectively.
\end{abstract}

Keywords: Indirect ELISA, Oesophagostomum columbianum, goat

\section{Introduction}

Nodular enteritis due to Oesophagostomum columbianum is a common and widely prevalent parasitosis with significant economic importance in small ruminant livestock (Olivares et al., 2001) throughout the Asian subcontinent (Khan, 1989; Mohanta et al., 2007). Caprine oesophagostomosis, like most of the helminth infections, is insidious and chronic in nature and the migratory prepatent stages of the parasite are involved in its major pathogenic effect. Reliable detection of the active infection of $O$. columbianum is usually based upon evaluation of clinical signs and faecal examination, which have their inherent limitations. Clinical signs usually become apparent only when the infection is heavy and the eggs are passed in the faeces after the prepatent period of approximately 41 days (Soulsby, 1982) when the infection is much advanced and the major damage is already done. In order to circumvent these limitations there is an acute need for developing a reliable serological assay like enzyme linked immunosorbent assay (ELISA) for early detection of the infection. Detection of serum antibodies against parasite by ELISA is a rapid and simple test with which a considerable number of samples could be processed at the same time. Furthermore, seroepidemiological studies involving examination of large group of animals might also benefit from a reliable ELISA. Usually such a test, in contrast to faecal examination, is less time consuming.

Therefore an indirect ELISA based on crude somatic antigen of $O$. columbianum was standardized and evaluated under field conditions as a diagnostic tool for detection of anti-O. columbianum antibodies in sera of infected goats.

\section{Materials and methods}

Experimental animals

Twenty helminth free Bengal goats (Capra hircus), $30-$ 45-day-old, were maintained under intensive rearing con- 
ditions precluding accidental parasitic infections. At the age of five months they were used for experimental infection with $O$. columbianum.

Collection of Oesophagostomum columbianum $L_{3}$ and experimental infection

The infective $\mathrm{L}_{3}$ were obtained by culturing (Soulsby, 1982) the eggs separated from the adult female worms recovered from the caecum and colon of slaughtered goats (Johnson et al., 2004). The $\mathrm{L}_{3}$ at the dose rate of 600 per $\mathrm{kg}$ body wt. were orally administered in two of the 20 helminth free goats, after overnight withdrawal of feed, to serve as donors for sufficient number of monospecific $O$. columbianum eggs for artificial infection.

After the patency of the infection the faeces of the donor goats was cultured (Soulsby, 1982) and the $\mathrm{L}_{3}$ were harvested (Anon, 1971). These $\mathrm{L}_{3}$ were used for artificial infection of twelve goats as stated earlier keeping the remaining six goats as uninfected control. Serum samples of the infected as well as the control goats were collected on every third day post-infection (DPI) till $33 \mathrm{DPI}$, following the standard methods and they were preserved at $-20{ }^{0} \mathrm{C}$ for use in the assay.

\section{Preparation of Oesophagostomum columbianum antigen}

For preparation of crude somatic antigen (CSAg) $O$. columbianum from the caecum and colon of freshly slaughtered goats was collected (Johnson et al., 2004) in a Petri dish containing $0.15 \mathrm{M}$ phosphate buffer saline (PBS), pH-7.2. The worms were washed $4-5$ times in the same buffer and finally 300 worms were homogenized in $10 \mathrm{ml}$ of cooled $0.15 \mathrm{M}$ PBS (pH-7.2) containing $25 \mathrm{mM}$ phenylmethyl sulfonyl fluoride (PMSF) and $24 \mathrm{mM}$ ethy- lene-diamine tetraaceticacid (EDTA) in a glass tissue homogenizer. Homogenized parasites were disintegrated using Ultra Sonicator (NISSEI, Japan). The disintegrated parasite extract was centrifuged at $4{ }^{\circ} \mathrm{C}$ at $2000 \mathrm{~g}$ for 45 minutes and the supernatant was collected as the CSAg with a protein concentration of $3.82 \mathrm{mg} / \mathrm{ml}$ specified according to Lowry et al. (1951). The antigen was stored at $20{ }^{\circ} \mathrm{C}$ for use in the assay.

\section{Standardization of the assay}

The antibody detection was performed according to the method of Voler et al. (1976) with some modifications. The optimal concentration of ELISA reagents including the concentration of the coating antigen $(5 \mu \mathrm{g} / \mathrm{well})$, dilution of the positive and negative reference sera (1:100) as well as rabbit anti-goat IgG-horseradish peroxidase (HRP) conjugate $(1: 1000)$ and the optimal test conditions, respectively were determined by chequer board dilution assay using flat-bottom 96-well micro-ELISA plate (Nunc, Maxisorp). The absorbance (optical density; OD) of the wells was measured at $492 \mathrm{~nm}$ by an ELISA reader (Thermo, Japan). The mean OD plus three times the standard deviation of the negative control sera was taken as the cut-off value for considering a sample as test positive (Lejon et al., 2005).

\section{Performance of the assay}

The sensitivity, specificity and accuracy of the ELISA were determined (Thrusfield, 2003) using 96 serum samples of field goats collected at abattoir. The parasitological status of animals with regard to nematodes and cestodes in the abomasums, small and large intestines was carefully examined and recorded.

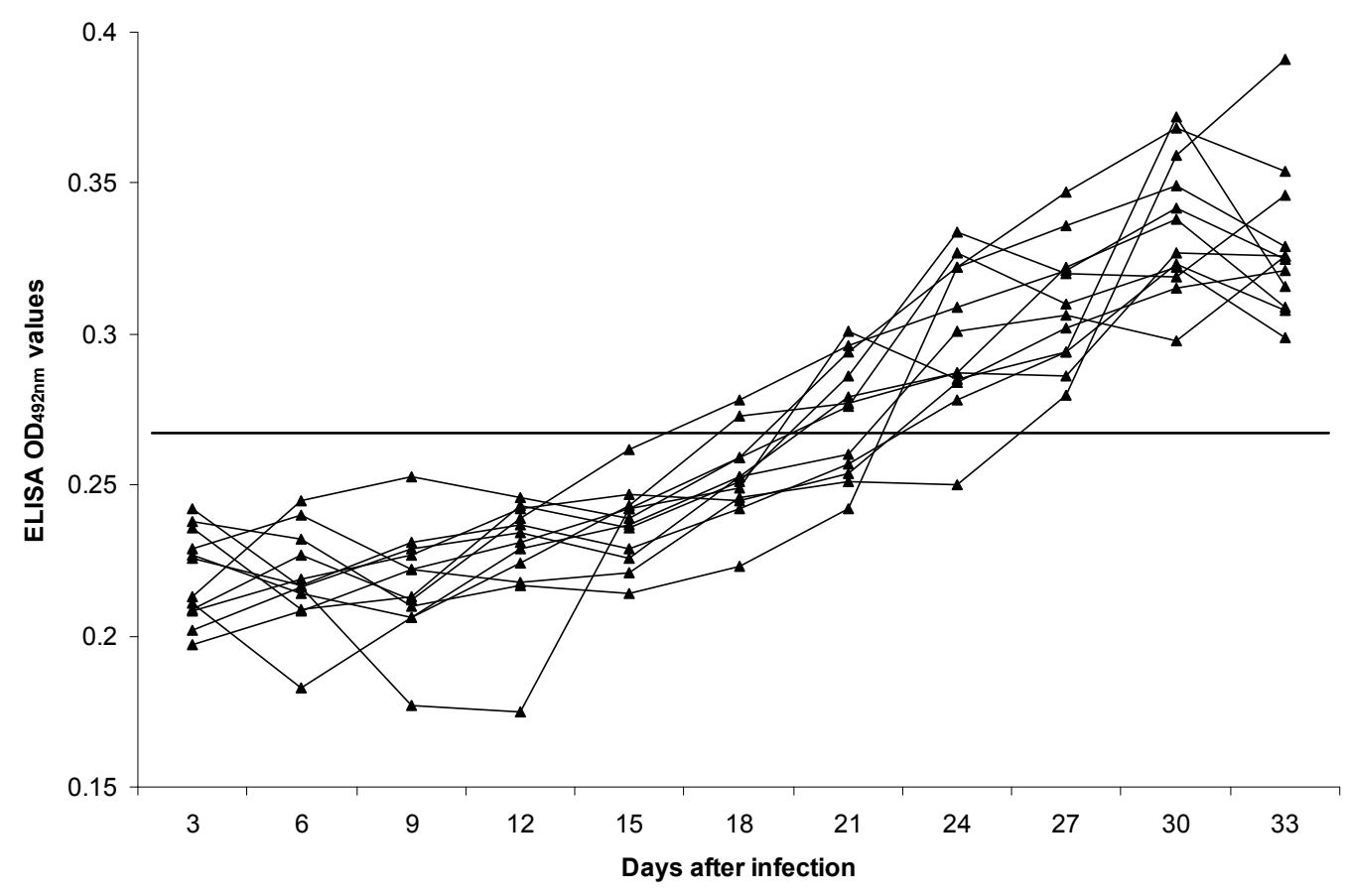

Fig. 1. Follow-up antibody detection in 12 goats during experimentally induced infection with $O$. columbianum 


\section{Results}

Antibody detection ELISA

The cut-off OD value for the standardized ELISA as determined was 0.268. O. columbianum antibodies in all experimentally infected goats were detected as early as 18 to 27 DPI (Fig. 1). The seroconversion was relatively long before the patency of the infection, which in this study was on 42 DPI. Specific antibodies were consistently present during the subsequent observation period i.e. till 33 DPI.

The results of the standardized ELISA performed on 96 sera samples of slaughtered goats with known parasitological status are presented in Fig. 2.

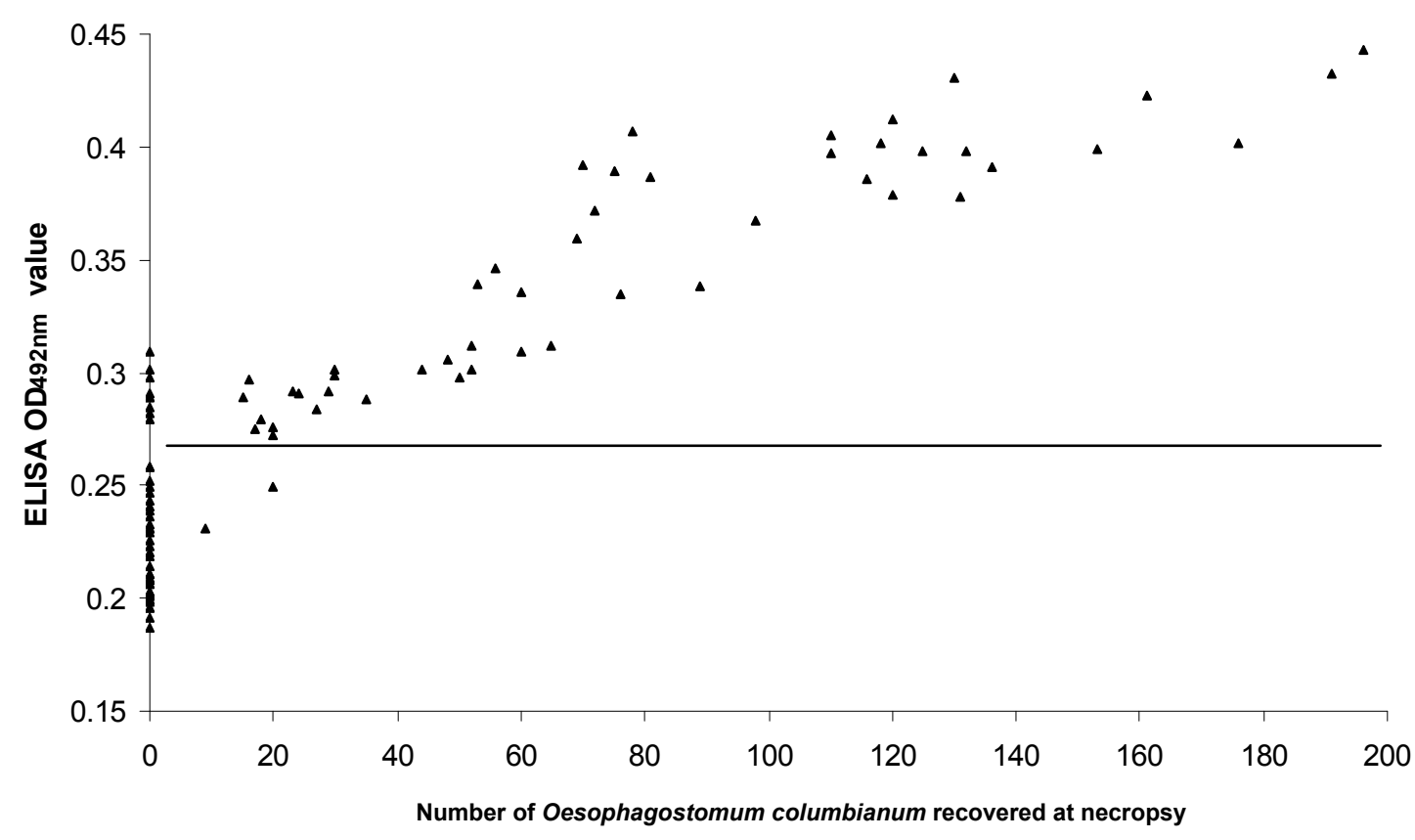

Fig. 2. Serum antibody level (OD values) in field goats $(n=96)$ with different levels of worm burden

Twenty-six of the 96 goats examined had no helminth infection in the gastrointestinal tract. Out of the 70 goats, which were positive for gastrointestinal helminths 50 and 20 goats had polyparasitism including and excluding $O$. columbianum, respectively. Other gastrointestinal helminths recorded included Haemonchus contortus, Trichostrongylus sp, Bunostomum sp, Gaigeria sp, Trichuris sp and tapeworms. Forty-eight of the 50 goats with polyparasitism including $O$. columbianum were positive in the assay, whereas 34 out of $46 O$. columbianum- negative goats were detected as negative in the assay. The remaining twelve goats with polyparasitism excluding $O$. columbianum were seropositive. These results are summarized in Table 1 . The sensitivity, specificity and accuracy of the present ELISA, as calculated, were $96 \%, 73.91 \%$ and $85.42 \%$, respectively.

\section{Discussion}

Diagnosis of gastrointestinal nematode infections has conventionally relied upon detection of the clinical signs, aided by qualitative detection of the eggs in the faeces of suspected animals. Effectiveness of these methods is how-

Table 1. Performance status of the antibody-ELISA on field sera of goat with known parasitological status on necropsy

\begin{tabular}{|c|c|c|c|}
\hline \multirow[t]{3}{*}{$\begin{array}{c}\text { Number of } \\
\text { examined goats }\end{array}$} & \multirow{2}{*}{$\begin{array}{c}\text { Number of } O \text {. columbianum } \\
\text { positive goats and other g. i. } \\
\text { parasites on autopsy }\end{array}$} & \multicolumn{2}{|c|}{$\begin{array}{l}\text { Number of Oesophagostomum sp. free and other g. i. } \\
\text { parasites on autopsy }\end{array}$} \\
\hline & & G.I. parasites free goats & Presence of other g.i. parasites \\
\hline & ELISA + ve* & ELISA + ve & ELISA - ve \\
\hline
\end{tabular}


The standardized ELISA using easily available crude somatic antigen yielded promising results for detection of prepatent and patent oesophagostomosis in goats. In experimentally infected goats the infection was detected between $18-27$ days after the infection and it was obviously much earlier than the time required for the infection to reach the patent period (42 days in the present study). ELISA is known for its potential to detect the antibodies at a quite early stage of the infection. Nevertheless, it could detect the artificially induced oesophagostomosis only after 17 days of the infection.

The indirect ELISA was evaluated on field sera and the results were compared with the post-mortem findings with regard to the actual parasitological status. The assay proved high sensitivity (96\%), specificity (73.91\%) and accuracy $(85.42 \%)$ and holds considerable promise for its exploitation in seroepidemiological studies of this economically significant helminthosis. Sequestration of antibodies and the formation of circulating immune complexes (Gasser et al., 1993) and immune evasion mechanisms of the parasite (Spinelli et al., 1996) might be responsible for wide variations in the antibody level in the necropsy positive samples as shown by indirect ELISA. Two false negative results in the present assay might be due to low worm burden $(9-20)$ or poor immune response of the host (Gasser et al., 1994). Besides, host nutritional status (Jenkins et al., 1991; Gasser et al., 1992) and physiological and environmental factors like reinfection or coinfection with other parasites (Carmena et al., 2005) might also have an impact on the antibody levels. False positive result of the assay with postmortem negative samples might be due to the persistence of antibodies to the past infection, which might have been eliminated by anthelmintic medication. False positive result is probably due to cross reactivity of $\mathrm{O}$. columbianum with other helminths. Cross reactivity amongst different helminths is a common and limiting factor in the development of serological tests against helminth infection (Philipp \& Rumjaneck 1984; Cuquerella et al., 1994; Molina et al., 1999). The short comings of antibody ELISA in the diagnosis of helminth infections would best be overcome using antigen detection ELISA. Copro-ELISA assay could be the best possible tool for detection of current infection of gastrointestinal parasites and attempts in this regard have already been made (Johnson et al., 2004; Jas et al., 2010).

The standardized assay offers the potential for its development as one of good diagnostic tools for oesophagostomosis. The use of purified antigen may minimize cross reactivity with other worms.

\section{Acknowledgements}

The authors thankfully acknowledge the financial assistance of the Indian Council of Agricultural Research, New Delhi in conducting this study under the research project entitled "All India Network Programme on Gastrointestinal Parasitism."

\section{References}

ANON. (1971): Manual of Veterinary Parasitological Laboratory Techniques, Technical Bulletin No. 18, Her Majesty's Stationery Office, Ministry of Agriculture, Fisheries and Food, London, U. K.

Carmena, D., Benito, A., Martinez, J., Guisantes, J. A. (2005): Preliminary study of the presence of antibodies against excretory-secretory antigens from protoscoleces of Echinococcus granulosus in dogs with intestinal echinococcosis. Mem. Inst. Oswaldo. Cruz., 100 (3): 311 - 317 Cuquerella, M., Munoz, M. T. G., Carrera, L., Fuente, C. D. L., AlundA, J. M. (1994): Cross antigenicity among ovine Trichostrongyloidea. Preliminary report. Vet. Parasitol., 53: $243-251$

Gasser, R. B., Jenkins, D. J., Heath, D. D., Lawrence, S. B. (1992): Use of Echinococcus granulosus worm antigens for immunodiagnosis of Echinococcus granulosus infection in dogs. Vet. Parasitol., 45: $89-100$

Gasser, R. B., Jenkins, D. J., Paolillo, E., Parada, L., CABrera, P., Craig, P. S. (1993): Serum antibodies in canine echinococcosis. Intl. J. Parasitol., 23: 579 - 586

Gasser, R. B., Parada, L., Acuna, A., Burges, C., Laurenson, M. K., Gulland, F. M. D., Reichel, M. P., PAOLILLO, E. (1994): Immunological assessment of exposure to Echinococcus granulosus in a rural dog population in Uruguay. Acta Trop., 58: $179-185$

JAS, R., GHOSH, J. D., DAS, K. (2010): Polyclonal antibody based coproantigen detection immunoassay for diagnosis of Oesophagostomum columbianum infection in goats. Vet. Parasitol., (In press), doi: 10.1016/j.vetpar.2010.02.013.

Jenkins, D. J., GAsser, R. B., Romig, T., ZeYhle, E. (1991): Antibody responses against natural Taenia hydatigena infection in dogs in Kenya. Int. J. Parasitol., 21: 251 $-253$

Johnson, D. A., Behnke, J. M., Coles, G. C. (2004): Coproantigen capture ELISA for the detection of Teladorsagia (Ostertagia) circumcincta in sheep improvement of specificity by heat treatment. Parasitology, 129 (1): 115 - 126 KHAN, S. C. (1989): Studies on the incidence, development of parasitic stages and histopathology of "Nodular Worms" of goats (Capra hircus). M.V.Sc. thesis, West Bengal, India: Bidhan Chandra Krishi Vishwavidyalaya, Lejon, V., Claes, F., Verloo, D., Maina, M., UraKaWa, T., Majiwa, P. A. O., Buscher, P. (2005): Recombinant RoTat 1.2 variable surface glycoprotein as antigen for diagnosis of Trypanosoma evansi in dromedary camels. Int. J. Parasitol., 35: 455 - 460

Lowry, O. H., Rosebrough, N. J., FARR, A. B., RANDAll, R. J. (1951): Protein measurement with the Folin-phenol reagent. J. Biol. Chem., 193: 265

Mohanta, U. K., Anisuzzaman, Farjana, T., Das, P. M., Majumder, S., Mondal, M. M. H. (2007): Prevalence, population dynamics and pathological effects of intestinal helminths in Black Bengal goats. B. J. Vet. Med., 5(1\&2): $63-69$ 
Molina, J. M., Ruiz, A., Rodriguez-Ponce, E., Gutierrez, A. C., Gonzalez, J., Hernandez, S. (1999): Cross - reactive antigens of Haemonchus contortus adult worms in Teladorsagia circumcincta infected goats. Vet. Res., 30 (4): 393 - 399

Olivares, J. L., Rodriguez, D. J. G., Herrera, H., Cortes, S., Gonzalez, O. (2001): Experimental Oesophagostomum columbianum infection in ovines. Rev. Salud Anim., 23: 118 - 122

Philipe, M., RumjaneCK, F. D. (1984): Antigenic and dynamic properties of helminth surface structures. Mol. Biochem. Parasitol., 10: 245 - 268

RECEIVED OCTOBER 8, 2009
SoulsBy, E. J. L. (1982): Helminths, arthropods and protozoa of domesticated animals. $7^{\text {th }}$ Edition. The English Language Book Society and Bailliere, Tindall, London. Spinelli, P., Carol, H., Nieto, A. (1996): Niveles de anticuerpos y antigenos circulantes en perros con infection natural y experimental por Echinococcus granulosus. Immunologia, 15: $21-29$

THRUSFIELD, M. (2003): Veterinary Epidemiology. $2^{\text {nd }}$ Edition. Blackwell Science, $134-135$ pp.

Voller, A., Bidwell, D. E., Bartlelt, A. (1976): Enzyme immunoassay in diagnostic medicine. Bull. World Health Organ., 53: 55 - 65

ACCEPTED MARCH 5, 2010 